\title{
Great expectations: views of genetic research participants regarding current and future genetic studies
}

Gail Henderson, $P h D^{1}$, Joanne Garrett, $P h D^{2}$, Jada Bussey-Jones, $M D^{3}$, Mairead Eastin Moloney, $\mathrm{MA}^{2}$, Connie Blumenthal, $M P H^{2}$, and Giselle Corbie-Smith, $M D, M S c^{1}$

\begin{abstract}
Purpose: Recruitment of prior participants in genetic research is one strategy suggested to maximize efficient use of research dollars in gene-environment studies. We explored attitudes toward genetic research participation among people in a case-control genetic epidemiology study of colon cancer, the North Carolina Colorectal Cancer Study (NCCCS). Methods: Quantitative and qualitative cross-sectional analysis of 801 NCCCS participants. Results: Participants were "very positive" (63\%) or "positive" (32\%) about genetic research, and "very likely" (49\%) or "somewhat likely" (40\%) to participate in future genetic research. Variables significantly associated with feeling "very positive" were white race, more education, nonreligious, hearing "a lot" about genetic research, and two measures of trust in medical research. Except for race and education, the same variables were significantly associated with being "very likely" to participate in future studies. Qualitatively, "good things" for self and family included discovering causes and cures for cancer, and the value of genetic information. Many could not list "bad things"; those who did mentioned anxiety, "knowing too much," losing confidentiality, or abuse of information. Conclusions: Despite very positive attitudes of these participants toward genetic research, there is significant variation based on participant characteristics. These findings should encourage and caution researchers attempting to recruit prior participants into genetic studies. Genet Med 2008:10(3):193-200.
\end{abstract}

Key Words: genetic research participants, research ethics, minority recruitment, genetic information, genetic epidemiology studies

A large and diverse group of research participants is critical to the study of genetic variation, gene-environment interaction, and disease expression. ${ }^{1}$ Through its extramural and intramural research programs, the National Human Genome Research Institute (NHGRI) has promoted such large-scale genomic studies. Recruiting subjects who participated in previous genetic research studies is one strategy that has been suggested in these initiatives to maximize efficient use of research dollars. People who have participated in research studies or in clinical contexts may be more positive about a request to use previously collected biological samples or may be more willing to participate in future genetic studies than people in the general population ${ }^{2}$; however, these propensities have not been

\footnotetext{
From the ${ }^{1}$ Department of Social Medicine, and the ${ }^{2}$ Sheps Center for Health Research, University of North Carolina School of Medicine, Chapel Hill, North Carolina; and the ${ }^{3}$ Department of Medicine, Emory University School of Medicine, Atlanta, Georgia.

Gail Henderson, PhD, Department of Social Medicine, 347 A MacNider, 333 South Columbia Street, University of North Carolina School of Medicine, Chapel Hill, NC 27599-7240. E-mail: ghenders@med.unc.edu.

Disclosure: The authors declare no conflict of interest.

Submitted for publication September 4, 2007.

Accepted for publication December 6, 2007.

DOI: 10.1097/GIM.0b013e318164e4f5
}

the subject of systematic evaluation. Few studies have explored the attitudes of such individuals who now seem to represent an important resource for genetic research. To address this gap in the literature, we interviewed individuals who had participated in a genetic epidemiology study, examining their attitudes, positive as well as negative, toward genetic research, and how likely they would be to participate in a genetic research study in the future.

\section{METHODS}

\section{The LeARN Study and North Carolina Colorectal Cancer Study}

Learning About Research in North Carolina (LeARN) uses a cross-sectional design to study African American and white individuals who recently participated in a case-control genetic epidemiology study of colon cancer risk factors, the North Carolina Colorectal Cancer Study (NCCCS). In the NCCCS study, cases had an initial diagnosis of invasive colorectal cancer, and controls were drawn from Department of Motor Vehicles (DMV) records and Medicare (HCFA) beneficiary lists. Race was initially obtained from cancer registry records and DMV or HCFA files and further confirmed by self-identification during the interview. In the case of conflicting data, the participants' self-identified race was used. The NCCCS partic- 
ipants completed a 2-hour in-person interview that collected data on demographics; dietary, lifestyle, and environmental exposure; and health care access and utilization. Blood and/or a mouthwash sample were obtained from consenting participants at the conclusion of the interview. Individuals were asked to consent to storage of residual DNA and serum for future analyses. In the final NCCCS study, $22 \%$ of the respondents were African American and 51\% were cases. Of the respondents interviewed during the time period that LeARN was recruiting from NCCCS, 21\% were African American and 45\% were cases.

Potential participants for the LeARN telephone interviews were identified through the NCCCS database of subjects interested in hearing about other studies. They were eligible if they met the following criteria: (1) self-reported race of African American or non-Latino white, (2) completed the entire NCCCS interview, (3) agreed to be contacted about future studies, (4) lived in the state of North Carolina at the time of the LeARN study, and (5) cognitive functioning as assessed by the interviewer was sufficient to allow successful completion of the telephone interview.

Potential participants were mailed a letter by the NCCCS investigators that introduced the LeARN study, described the telephone interview, and alerted them to expect a follow-up telephone call. Participants were given a toll-free number to call the NCCCS offices and invited to call with questions or if they did not wish to be contacted. Potential participants were contacted on average 4 months after completing the NCCCS interview. During the initial phone call, the nature and purpose of the LeARN study was explained and verbal consent was sought. Each participant was offered an incentive of $\$ 25$, which was mailed after completion of the interview. We contracted with a professional survey group, FGI, Inc., to conduct the 45-minute telephone interviews, which consisted of both closed and open-ended questions, using Computer-Assisted Telephone Interviewing methods. All interviews were audiotaped and transcribed for content analysis of the open-ended questions. All procedures were approved by the UNC Institutional Review Board.

We asked participants questions on a range of topics having to do with research participation. The final LeARN Participant Questionnaire contained 94 items-16 open-ended and 78 closed-ended questions - and took on average 44 minutes to complete. To address external and internal validity, we conducted extensive formative research and pilot testing that employed a range of methods, including cognitive interviews, focus groups, and in person or telephone pilot interviews to refine the questionnaire.

\section{LeARN variables and analytic approaches}

This analysis focuses on two main quantitative outcomes, each derived from the answers to a 5-point Likert scale question: (1) "Overall, how positive or negative do you feel about this kind of genetic research, the kind that looks at whether genes put people at risk for disease or illness" ("very positive" to "very negative"), and (2) "How likely would you be to take part in such a study in the future" ("very likely" to "very unlikely"). Because most of the participants answered positively to both these questions, we dichotomized each response at the highest category, i.e., "very positive" versus the other responses for the first question, and "very likely" versus the other responses for the second question.

We were interested in seeing whether characteristics of the LeARN participants were associated with responses to these two questions. We used means and frequencies to describe demographic information (e.g., age, race, gender, education) and other characteristics, such as case/control status, perceived health status, how much they had heard about genetic research, and two measures of trust in medical researchers. For the analyses, we collapsed years of education into a four-category variable; a three-category variable was created for religion, based on a combination of two questions that asked whether respondents are not at all, somewhat, or very religious and whether they rely on religion when times are tough not at all, somewhat, or a great deal (questions drawn from the North Carolina Breast Cancer Screening Project, an eight-year study examining the effects of mammography in rural North Carolina); and a four-category variable was created for cancer history, which differentiated cases and controls by whether they had a relative who had ever been diagnosed with cancer.

We tested associations between these participant characteristics and each of the dichotomous outcomes, using t-tests to calculate mean age differences, and $\chi^{2}$ tests for the comparisons of each outcome to all other variables. Finally, we fit separate logistic regression models for each outcome to determine which set of characteristics remained statistically significant $(P \leq 0.05)$ after adjustment for all other variables in the model. We included all variables in the initial models, whether significant or not in bivariate comparisons. We did not include income in these models because of a large number of missing values. Also, because there were no differences in people who felt positive about genetic research and the first three levels of education (less than high school, high school grad, and technical school and/or some college), we collapsed these groups into one category and compared them with college graduates. All four education categories were used for the outcome of how likely they were to participate in the future. We used likelihood ratio tests to remove nonsignificant variables $(P>0.05)$ from the models. Variables that remained are reported as adjusted percents (of "very positive" or "very likely") estimated from the beta coefficients of the final reduced models.

A subsample of 194 of the LeARN population was created to explore respondents' perceptions of genetic research qualitatively, based on responses to open-ended questions. The primary goal of this subsample was to examine race differences in views of the causes of colorectal cancer and views of research that focuses specifically on race and genetic links to health. At the time of subsample creation, there were 97 African American respondents and we decided to include them all. We added an equal number of white respondents, matched by case status, age, education, and sex. Although this subsample was created 
for other analyses, we have used some of these qualitative responses to complement our quantitative results.

In this analysis, we examined responses to four open-ended questions: (1) "List the good things for yourself and your family about taking part in genetic research studies"; (2) "List the good things for society about taking part in genetic research studies"; (3) "List the bad things for yourself and your family ... "; and (4) "List the bad things for society...". Qualitative codes were initially developed for responses to all open-ended questions by the team of LeARN investigators. They were applied, and validated through an iterative process. Three team members coded all responses to open-ended questions, reviewing codes for $10 \%$ of transcripts together, to assure uniformity of application. For the subsample of 194, four investigators worked in pairs to further validate the codes for the four questions used in this article.

\section{RESULTS}

The overall response rate in the LeARN study was $73 \%$. The final sample of 801 respondents included 19\% African Americans and $81 \%$ whites, $45 \%$ were cases and $55 \%$ controls (Table 1). The majority had at least a high school education, and $28 \%$ had a college degree. About half the sample had an annual income of less than $\$ 40,000$. The mean age of the respondents was 64 years, and $57 \%$ were male. Most were "very" (53\%) or "somewhat" (42\%) religious. Most said they had heard about genetic research and expressed trust in medical researchers. Compared with the larger sample of 801, the subsample includes more African Americans (by design), and some of the demographic characteristics are consistent with the intentional over-sampling (i.e., lower education and income). Most other variables are similar, however, and there was no difference between the two samples in responses to the two outcome variables: how positive people felt about genetic research and how likely they were to participate in future studies.

\section{Positive views of genetic research}

When asked, "Overall, how positive or negative do you feel about this kind of genetic research, the kind that looks at whether genes put people at risk for disease or illness," most were "very positive" (63\%) or "positive" (32\%) about genetic research (Table 1). Most reported being "very likely" (49\%) or "somewhat likely" (40\%) to participate in a genetic research study in the future.

What is behind these positive opinions about genetic research? Qualitative analyses of the subsample of 194 provide some insight. When asked to list "the good things" about taking part in genetic research studies, for self and family and for society, respondents' answers focused on current and future contributions to improving health. Specifically, "good things" for self and family included the potential for discovering the causes of diseases such as cancer, even "eventually finding a cure for all types of cancer whether it's colon, breast, or whatever." Many respondents commented on the value of genetic information. One said, "The more you know about anything
Table 1

Characteristics of the sample $(\mathrm{n}=801)$

\begin{tabular}{|c|c|c|}
\hline Characteristic & $n$ & $\begin{array}{l}\text { Percent or } \\
\text { mean (SD) }\end{array}$ \\
\hline \multicolumn{3}{|l|}{ Race } \\
\hline African American & 153 & 19 \\
\hline White & 648 & 81 \\
\hline \multicolumn{3}{|l|}{ Education } \\
\hline Less than high school & 118 & 15 \\
\hline High school grad & 197 & 25 \\
\hline Technical or some college & 258 & 32 \\
\hline College degree, graduate school & 228 & 28 \\
\hline Age (yr) & 800 & $64.3(9.90)$ \\
\hline \multicolumn{3}{|l|}{ Gender } \\
\hline Male & 457 & 57 \\
\hline Female & 344 & 43 \\
\hline \multicolumn{3}{|l|}{ Income } \\
\hline Less than $\$ 20,000$ & 147 & 21 \\
\hline$\$ 20,000$ to $\$ 40,000$ & 183 & 27 \\
\hline More than $\$ 40,000$ & 361 & 52 \\
\hline \multicolumn{3}{|l|}{ How religious } \\
\hline Not religious & 40 & 5 \\
\hline Somewhat religious & 326 & 42 \\
\hline Very religious & 413 & 53 \\
\hline \multicolumn{3}{|l|}{ Perceived health status } \\
\hline Excellent & 105 & 13 \\
\hline Very good & 294 & 37 \\
\hline Good & 235 & 30 \\
\hline Fair & 113 & 14 \\
\hline Poor & 45 & 6 \\
\hline \multicolumn{3}{|l|}{ Case/control status } \\
\hline Case & 363 & 45 \\
\hline Control & 438 & 55 \\
\hline \multicolumn{3}{|l|}{ Cancer history } \\
\hline Case, family history (relative) & 51 & 6 \\
\hline Case, no family history (relative) & 312 & 39 \\
\hline Control, family history (self or relative) & 144 & 18 \\
\hline Control, no family history (self or relative) & 294 & 37 \\
\hline \multicolumn{3}{|l|}{ How much heard about genetic research } \\
\hline A lot & 279 & 35 \\
\hline Little & 460 & 58 \\
\hline None & 56 & 7 \\
\hline \multicolumn{3}{|l|}{ Trust medical researchers } \\
\hline Agree & 740 & 93 \\
\hline \multirow[t]{2}{*}{ Disagree or don’t know } & 59 & 7 \\
\hline & & (Continued) \\
\hline
\end{tabular}


Table 1

Continued

\begin{tabular}{lrc}
\hline Characteristic & $n$ & $\begin{array}{c}\text { Percent or } \\
\text { mean (SD) }\end{array}$ \\
\hline Researchers want to know more than they need to know & & \\
Agree & 153 & 19 \\
Disagree or don't know & 647 & 81 \\
How positive about genetic research & 489 & 63 \\
Very positive & 253 & 32 \\
Positive & 41 & 5 \\
Neutral or not positive & & \\
How likely to take part in genetic research & 377 & 49 \\
Very likely & 308 & 40 \\
Somewhat likely & 82 & 11 \\
Neutral or unlikely & & \\
\hline
\end{tabular}

the better off you are." They mentioned increased awareness and preventive health activities that might reduce or eliminate the risk of disease. As one noted, "If they find that genes (are) running in their family, they can keep a closer check on it," and although that individual might not benefit, "... it may help someone else in my family that comes behind me" or simply help "prepare to deal with the illness later in life." A few mentioned genetic testing and counseling as positives, and also gene altering. Although most of the responses regarding "good things" for society were similar, a few additional items emerged. Specifically, some participants spoke of financial benefits for society stemming from reduced medical expenditures, increasing productivity due to reduced illnesses, dropping insurance rates, and overall reduction in the emotional burden and stress of disease. Some respondents focused on their expectation for medical breakthroughs, and belief in the inevitability of medical progress, which will "take a long time." Researchers received kudos from some as "a dedicated bunch of people that really want to see these cures... not for their own glorification."

When we compared characteristics of the 801 respondents to the views on genetic research and participating in future studies, African Americans were somewhat less likely than whites to say they feel "very positive" about genetic research ( $52 \%$ vs. $65 \%, P=0.004$ ), but there was no significant difference between these two groups' responses to being "very likely" to participate in future genetic studies ( $44 \%$ vs. $50 \%, P=$ $0.153)$ (Table 2). Other respondent characteristics significantly associated both with feeling "very positive" about genetic research and with being "very likely" to participate in future studies included having a college degree, not being religious, having heard a lot about genetic research, agreeing with the statement that they "trust medical researchers," and disagreeing with the statement that "researchers want to know more than they need to know." Other variables, including case-control status and cancer history, were not related to either outcome.
After adjustment for all other variables in the model, the following variables remained significantly associated with feeling "very positive" about genetic research (Table 3 ): white race (66\% vs. $56 \%, P=0.035)$, more education ( $72 \%$ vs. $61 \%, P=$ 0.010 ), not being religious ( $84 \%$ vs. $58 \%$ and $67 \%, P=0.004$ ), hearing "a lot" about genetic research ( $76 \%$ vs. $57 \%$ and $58 \%$, $P<0.001)$, agreeing that they "trust medical researchers" ( $66 \%$ vs. $40 \%, P=0.001$ ), and disagreeing with the statement that "researchers want to know more than they need to know" ( $54 \%$ vs. $67 \%, P=0.007$ ). With the exception of race and education level, the same variables remained significantly associated with being "very likely" to participate in future genetic studies.

\section{Negative views of genetic research}

When respondents were asked to list the "bad things" for self and family, or for society, half of the qualitative subsample of 194 said "none." Some respondents were emphatic in asserting "none," justifying this response by the value of the research, e.g., "None, because anything that helps is worth doing." For others, "none" meant that they could not think of any bad things: "I don't know of any bad things, I think the research is very important, I really don't see any bad parts." For still others, "none" was followed by qualifications that revealed underlying concerns that the goals of research participation were presented honestly and completely: "None, as long as it's voluntary and for the purpose stated," "None, if they are doing the study to find the truth, the causes of disease," "None unless they lie to you about it," "None except if it is detected but can't be prevented," "None unless you give a needle and give somebody some kind of disease."

Despite generally positive assessments, respondents did list some concerns. Interestingly, these did not vary in number or type when African Americans responses were compared with those of whites in the subsample. The most common concern was anxiety about the implications of the genetic information. Respondents worried about knowing "too much," about "knowing what conditions we are facing," "realizing there is no treatment or prevention," and "if you take that to heart and start concentrating on it and worrying about it." There was concern that people may not want to know this information, that "people are not interested in knowing what their fate could be," "maybe it's best that you don't know," that facing it is "not bad, but hard." Other concerns included failing to maintain the confidentiality of sensitive information collected; as one participant said, "you are judged if the information is given out to employers or. . . [if the] government actually used it against you and starts categorizing people." Another worried that "researchers perhaps don't use this material appropriately." Similar issues were described when respondents were asked to list "bad things" for society, although a few took the opportunity to focus again on the benefits of genetic research for society, arguing that the "bad" thing is people who will not participate. One noted a citizen's responsibility to participate because all will benefit from the results. Lastly, two respondents warned that the good will of research participants might 
Table 2

Bivariate comparisons of sample characteristics by "how positive or negative you feel about this kind of genetic research" (very positive vs. other), and by "how likely would you be to take part in a genetic research study in the future" (very likely vs. other)

\begin{tabular}{|c|c|c|c|c|c|}
\hline \multirow[b]{2}{*}{ Characteristic } & \multirow[b]{2}{*}{$n$} & \multicolumn{2}{|c|}{ Feel very positive } & \multicolumn{2}{|c|}{ Very likely to participate } \\
\hline & & $\%$ or mean & $P$ & $\%$ or mean & $P$ \\
\hline \multicolumn{6}{|l|}{ Race } \\
\hline African American & 146 & 52 & 0.004 & 44 & 0.153 \\
\hline White & 637 & 65 & & 50 & \\
\hline \multicolumn{6}{|l|}{ Education } \\
\hline Less than high school & 110 & 58 & 0.015 & 50 & 0.024 \\
\hline High school grad & 193 & 59 & & 42 & \\
\hline Technical or some college & 254 & 59 & & 48 & \\
\hline College degree, graduate school & 226 & 71 & & 57 & \\
\hline Age (yr) ("very" vs. "other") ${ }^{a}$ & 782 & $64.5 / 63.8$ & 0.328 & $64.3 / 63.9$ & 0.435 \\
\hline \multicolumn{6}{|l|}{ Gender } \\
\hline Male & 448 & 63 & 0.530 & 51 & 0.178 \\
\hline Female & 335 & 61 & & 46 & \\
\hline \multicolumn{6}{|l|}{ Income } \\
\hline Less than $\$ 20,000$ & 143 & 60 & 0.096 & 51 & 0.850 \\
\hline$\$ 20,000$ to $\$ 40,000$ & 180 & 58 & & 53 & \\
\hline More than $\$ 40,000$ & 358 & 67 & & 51 & \\
\hline \multicolumn{6}{|l|}{ How religious } \\
\hline Not religious & 38 & 82 & 0.007 & 71 & 0.003 \\
\hline Somewhat religious & 322 & 58 & & 44 & \\
\hline Very religious & 402 & 65 & & 52 & \\
\hline \multicolumn{6}{|l|}{ Perceived health status } \\
\hline Excellent & 103 & 67 & 0.403 & 58 & 0.134 \\
\hline Very good & 287 & 65 & & 51 & \\
\hline Good & 232 & 58 & & 44 & \\
\hline Fair & 108 & 62 & & 45 & \\
\hline Poor & 45 & 58 & & 52 & \\
\hline \multicolumn{6}{|l|}{ Case/Control Status } \\
\hline Case & 352 & 61 & 0.311 & 49 & 0.764 \\
\hline Control & 431 & 64 & & 50 & \\
\hline \multicolumn{6}{|l|}{ Cancer history } \\
\hline Case, family history (relative) & 50 & 56 & 0.637 & 48 & 0.150 \\
\hline Case, no family history (relative) & 302 & 61 & & 49 & \\
\hline Control, family history (self or relative) & 142 & 63 & & 58 & \\
\hline Control, no family history (self or relative) & 289 & 65 & & 46 & \\
\hline \multicolumn{6}{|l|}{ How much heard about genetic research } \\
\hline A lot & 277 & 75 & $<0.001$ & 58 & 0.002 \\
\hline Little & 449 & 55 & & 44 & \\
\hline \multirow[t]{2}{*}{ None } & 52 & 54 & & 48 & \\
\hline & & & & & tinued) \\
\hline
\end{tabular}


Table 2

Continued

\begin{tabular}{|c|c|c|c|c|c|}
\hline \multirow[b]{2}{*}{ Characteristic } & \multirow[b]{2}{*}{$n$} & \multicolumn{2}{|c|}{ Feel very positive } & \multicolumn{2}{|c|}{ Very likely to participate } \\
\hline & & $\%$ or mean & $P$ & $\%$ or mean & $P$ \\
\hline \multicolumn{6}{|l|}{ Trust medical researchers } \\
\hline Agree & 725 & 65 & $<0.001$ & 51 & $<0.001$ \\
\hline Disagree or don't know & 56 & 38 & & 19 & \\
\hline \multicolumn{6}{|c|}{ Researchers want to know more than they need to know } \\
\hline Agree & 148 & 50 & $<0.001$ & 36 & $<0.001$ \\
\hline Disagree or don't know & 634 & 65 & & 52 & \\
\hline
\end{tabular}

${ }^{a}$ First number is mean age for "very positive"; second number is mean age for "other."

Table 3

Adjusted percents $^{a}$ of characteristics associated with very positive about genetic research and very likely to participate

\begin{tabular}{|c|c|c|c|c|c|c|}
\hline \multirow[b]{2}{*}{ Characteristic } & \multicolumn{3}{|c|}{ Feel very positive } & \multicolumn{3}{|c|}{ Very likely to participate } \\
\hline & $n$ & Adjusted \% & $P$ & $n$ & Adjusted \% & $P$ \\
\hline Race & & & & & & NS \\
\hline African American & 140 & 56 & 0.035 & & & \\
\hline White & 613 & 66 & & & & \\
\hline Education & & & & & & NS \\
\hline Less than college & 537 & 61 & 0.023 & & & \\
\hline College graduate, graduate school & 216 & 72 & & & & \\
\hline \multicolumn{7}{|l|}{ Religious } \\
\hline Not religious & 37 & 84 & 0.002 & 37 & 71 & 0.003 \\
\hline Somewhat religious & 320 & 58 & & 313 & 43 & \\
\hline Very religious & 396 & 67 & & 390 & 52 & \\
\hline \multicolumn{7}{|l|}{ How much heard about genetic research } \\
\hline A lot & 267 & 77 & $<0.001$ & 262 & 58 & 0.002 \\
\hline Little & 434 & 56 & & 424 & 44 & \\
\hline None & 52 & 60 & & 54 & 50 & \\
\hline \multicolumn{7}{|l|}{ Trust medical researchers } \\
\hline Agree & 700 & 66 & $<0.001$ & 691 & 52 & $<0.001$ \\
\hline Disagree or don't know & 53 & 40 & & 49 & 20 & \\
\hline \multicolumn{7}{|c|}{ Researchers want to know more than they need to know } \\
\hline Agree & 140 & 54 & 0.007 & 138 & 36 & 0.001 \\
\hline Disagree or don't know & 613 & 67 & & 602 & 52 & \\
\hline
\end{tabular}

${ }^{a}$ Adjusted percents calculated using the beta estimates from a logistic regression model including statistically significant variables $(P<0.05)$.

have limits. As one said, "I think that the time of study is over and the time of finding out some of the causes and problems and cures would be here, now. We have donated to the research for so many years and talked about it for so many years."

\section{DISCUSSION}

As expected for a sample of individuals who have agreed to participate in genetic epidemiology research, the majority of
NCCCS participants interviewed for the LeARN project were positive or very positive about genetic research and described themselves as somewhat or very likely to participate in future studies. Our interviews revealed a number of positives about genetic research for these study participants. They included the potential to discover the causes of disease, and the value of awareness and information, which might lead to prevention strategies even without a cure. Society would benefit as well, especially if medical progress ultimately resulted in cost savings 
associated with a healthier population. Half of the qualitative subsample of respondents saw no negatives of genetic research, although in a few cases, "none" was accompanied by qualifications that revealed underlying concerns. Those who listed negatives mentioned anxiety from "knowing too much," loss of confidentiality, abuse of information, and possible discrimination. It is important to note that many of those who felt quite positive about genetic research were also able to list some of these negative consequences.

A number of studies have examined responses to the request to provide DNA for research purposes and to provide biological samples for long-term storage, examining perceptions of risks and benefits, and how those might vary depending upon the nature of the request and who is responding. These studies document faith in the potential of genetic research to contribute to improved health ${ }^{3,4}$ and different responses by majority and minority groups. ${ }^{3,5-8}$ For example, Chen and colleagues ${ }^{9}$ analyzed NIH Clinical Center consent forms for 61 studies, and found that although $87 \%$ of 1670 subjects authorized future use for any medical condition, fewer African Americans (75\%) did so. Sterling et al. ${ }^{2}$ reviewed empirical studies of the willingness of different racial/ethnic groups to participate in genetic research and found significantly lower acceptance related to minority group status and other demographic factors.

Several studies of individuals who were already participating in research demonstrated similar differences in response to the request for genetic samples. McQuillan and colleagues, ${ }^{5}$ for example, conducted interviews with 3201 NHANES (National Health and Nutrition Examination Survey) study participants and found African Americans, women, and those of older age were significantly less likely to consent to donate and store specimens. Moorman and colleagues ${ }^{6}$ interviewed 872 female genetic research participants, and reported that being African American, of older age, lower income, less education, higher occupation category, and having poorer health status were associated with being less likely to consent to enroll in a cancer genetics registry. Other studies of genetic research have identified specific concerns of a variety of groups, including minorities, that might explain different participation rates. These specific concerns include control of DNA, potential for misuse of genetic data, racial discrimination, stigmatization of those at genetic risk, and unequal access to potential benefits, including misuse for ancestry testing. $3,4,10-13$

In this study, we were able to explore the relationship between attitudes toward genetic research and a number of variables raised in these previous studies. We found that respondents were more likely to be "very positive" about genetic research if they were white, more educated, more knowledgeable about genetic research, and more trusting of medical researchers. Thus, despite the fact that the respondents had participated in a genetic epidemiology study (NCCCS), as well as the LeARN study, variations in their perceptions of genetic research reflect the same demographic factors that have been identified in the studies described earlier. The finding that those who are "not religious" are also more positive about genetic research, compared with those who are "somewhat" or "very" religious, indicates the need for more attention to the role of religion in attitudes toward genetic research. ${ }^{14,15}$ However, because these respondents represented only $5 \%$ of the total sample, this particular finding should be interpreted with caution.

Despite generally positive attitudes, it is clear that all prior participants are not equally receptive to the prospect of recruitment into future studies. Some participants expressed distrust of medical researchers, more than half had heard little about genetic research, and $7 \%$ of respondents reported a complete lack of knowledge about genetic research even though they had recently participated in a genetic study (Table 1 ). Those expressing this distrust or having little knowledge were much less likely to be willing to participate in future studies. These findings, and the concerns described in response to open-ended interview questions, represent potential barriers to recruitment and retention of participants from diverse backgrounds for all genomics studies. Focused interventions to help educate potential study participants about genetic research and efforts to demonstrate the trustworthiness of the research team might help encourage future study participation.

Many LeARN respondents expressed "great expectations" about genetic research studies and the promise of medical progress. These expectations coincide with positive attitudes that Americans hold regarding the potential of medical science to address major health conditions, even making us "better than well." 16,17 They are also good news for researchers who hope to enlist current genetic study subjects for additional studies or recruit patients into future studies. Yet, our results demonstrate that positive responses may also be associated with overly high expectations, and that good will toward medical research may not persist without "results." It is important that researchers and scientific leaders address such expectations through careful explanation of the goals, potential benefits, and limitations of genetic research for participants. Equally important, researchers must not assume that prior experience in genetic research guarantees the ability to articulate participants' reservations about the risks of this type of research.

Our study has several limitations. First, because LeARN participants were drawn from the North Carolina Colorectal Cancer Study, the generalizability of its findings is limited to individuals in North Carolina and those whom have joined similar genetic research studies. Individuals who have not joined such studies may have different and potentially less positive attitudes toward research participation. Additionally, although the LeARN response rate was quite good (73\%), there are biases inherent in the sample that further limit its generalizability. The response rate differed by race: $64.6 \%$ of African Americans participated compared with $75.4 \%$ of whites. Much of this difference is related to unusable telephone numbers and differences in response to callbacks; the number of African Americans and whites who refused to participate in the LeARN study was similar. However, it may be that differences between African Americans and whites about how positive they felt about genetic research conceivably could have been larger than we 
observed had we had been able to recruit both races equally. Finally, the LeARN project asks about participation in future studies, assessing intention, which is one step removed from behavior. Despite these limitations, the contributions of LeARN findings are highly relevant to current goals of recruiting genetic study participants. Similar to other reports in the literature, LeARN participants were very positive about the promise of genetic research. Yet, these participants also demonstrate concerns about genetic research studies that will need to be addressed to ensure future participation. Knowledge of barriers and facilitators gathered from this and other studies provides a roadmap to improve public understanding and acceptance of genomics research. ${ }^{18}$

\section{ACKNOWLEDGMENTS}

Support for this research was from two NHGRI grants (R01 HG0022830, P20 HG03387) and an NSRA training grant (T32 HS000032).

\section{References}

1. National Institute on General Medical Sciences. Report of the first community consultations on the responsible collection and use of samples for genetic research, September 25-26, 2000. Available at: http://www.nigms.nih.gov/news/reports/ community_consultation.html. Accessed June 2, 2002.

2. Sterling R, Henderson GE, Corbie-Smith G. Public willingness to participate in and public opinions about genetic variation research: a review of the literature. Am J Public Health 2006;96:1971-1978.

3. Bates BR, Lynch JA, Bevan JL, Condit CM. Warranted concerns, warranted outlooks: a focus group study of public understandings of genetic research. Soc Sci Med 2005;60:331-344.

4. Schulz A, Caldwell C, Foster S. "What are they going to do with the information?"
Latino/Latina and African American perspectives on the Human Genome Project. Health Educ Behav 2003;30:151-169.

5. McQuillan GM, Porter KS, Agelli M, Kington R. Consent for genetic research in a general population: the NHANES experience. Genet Med 2003;5:35-42.

6. Moorman PG, Skinner CS, Evans JP, Newman B, et al. Racial differences in enrolment in a cancer genetics registry. Cancer Epidemiol Biomarkers Prev 2004;13:1349-1354.

7. Schwartz MD, Benkendorf J, Lerman C, Isaacs C, et al. Impact of educational print materials on knowledge, attitudes, and interest in BRCA1/BRCA2: testing among Ashkenazi Jewish women. Cancer 2001;92:932-940.

8. Wang SS, Fridinger F, Sheedy KM, Khoury MJ. Public attitudes regarding the donation and storage of blood specimens for genetic research. Community Genet 2001; $4: 18-26$.

9. Chen DT, Rosenstein DL, Muthappan P, Hilsenbeck SG, et al. Research with stored biological samples: what do research participants want? Arch Intern Med 2005; 165: $652-655$.

10. Fisher CB, Wallace SA. Through the community looking glass: reevaluating the ethical and policy implications of research on adolescent risk and sociopathology. Ethics Behav 2000;10:99-118.

11. Furr LA. Perceptions of genetics research as harmful to society: differences among samples of African-Americans and European-Americans. Genet Test 2002;6:25-30.

12. Hoyo C, Reid ML, Godley PA, Parrish T, et al. Barriers and strategies for sustained participation of African-American men in cohort studies. Ethn Dis 2003;13:470 -476.

13. Tambor ES, Bernhardt BA, Rodgers J, Holtzman NA, et al. Mapping the human genome: an assessment of media coverage and public reaction. Genet Med 2002;4:31-36.

14. Parrott R. "Collective amnesia": the absence of religious faith and spirituality in health communication research and practice. Health Commun 2004;16:1-5.

15. Parrott R, Silk K, Raup Krieger J, Harris T, et al. Behavioral health outcomes associated with religious faith and media exposure about human genetics. Health Commun 2004;16:29-45.

16. Elliott C. Better than well: American medicine meets the American dream. New York: W. W. Norton \& Company Inc. 2003.

17. Rothman S, Rothman D. The Pursuit of Perfection: The Promise and Perils of Medical Enhancement New York Random House 2003.

18. Beskow LM, W. B. Ethical issues in genetic epidemiology and population genetics In: Coughlin S, Beauchamp T, DL W, editors. Ethics and epidemiology, 2nd ed. New York: Oxford University Press. In press. 